\title{
Effect of weld heat input on toughness and structure of HAZ of a new super-high strength steel
}

\author{
WANG JUAN, LI YAJIANG* and LIU PENG \\ Key Laboratory of Liquid Structure and Heredity of Materials, Ministry of Education, School of Materials Science \\ and Engineering, Shandong University, Jinan 250061, P.R. China \\ *Also at National Key Laboratory of Advanced Welding Production Technology, Harbin Institute of Technology, \\ Harbin 150001, P.R. China
}

MS received 5 December 2002

\begin{abstract}
Fracture morphology and fine structure in the heat-affected zone (HAZ) of HQ130 super-high strength steel are studied by means of SEM, TEM and electron diffraction technique. Test results indicated that the structure of HAZ of HQ130 steel was mainly lath martensite (ML), in which there were a lot of dislocations in the sub-structure inside ML lath, the dislocation density was about $(0 \cdot 3 \sim 0 \cdot 9) \times 10^{12} / \mathrm{cm}^{2}$. No obvious twin was observed in the HAZ under the condition of normal weld heat input. By controlling weld heat input $(E \leq 20 \mathrm{~kJ} / \mathrm{cm})$, the impact toughness in the $\mathrm{HAZ}$ can be assured.
\end{abstract}

Keywords. Super-high strength steel; heat-affected zone; fracture; fine structure.

\section{Introduction}

The super-high strength steel has very high strength (UTS $\geq 1200 \mathrm{MPa}$ ) and impact toughness but the weld crack easily formed in the heat-affected zone and caused the possibility of brittle fracture in the welded zone when the weld structure was in service. The heat-affected zone, as one weak spot in the whole welding joint zone of the super-high strength steel, was given close attention by many investigators (Guojiu et al 1992; Zengda et al 1999). The welding joint of the super-high strength steel experienced different weld thermal cycles, in which the change of microstructure in the heat-affected zone (HAZ) was most obvious.

At present, the research on microstructure of the high strength steel is concentrated on steels of tensile strength (UTS) $\leq 1000 \mathrm{MPa}$ (Akselen et al 1986; Yajiang et al 1997). However, nearly there exists no information about the welding research on super-high strength steel (UTS $\geq 1200 \mathrm{MPa}$ ) in the available literature. HQ130 steel, which has tensile strength of more than $1300 \mathrm{MPa}$, is a newly developed low carbon quenched-and-tempered steel used for engineering machinery.

In this paper, the difficulty to cut and prepare thin film sample was overcome and the toughness and the fine structure in the HAZ of HQ130 super-high strength steel was studied by using scanning electron microscope (SEM) and transmission electron microscope (TEM). It provides experimental basis for evaluating the micro-

*Author for correspondence structure performance in the HAZ of the super-high strength steel.

\section{Experimental}

HQ130 super-high strength steel in the test was in the quenched-and-tempered condition. The austenitizing temperature was $920 \pm 10^{\circ} \mathrm{C}$ and tempering temperature was $250^{\circ} \mathrm{C}$. The microstructure of HQ130 steel consisted of tempered martensite, which had high strength and good impact toughness. Chemical composition and mechanical properties of HQ130 steel after heat treatment (quenched and tempered at $250^{\circ} \mathrm{C}$ ) are given in table 1 .

The welded joint was prepared by using $\mathrm{Ar}+\mathrm{CO}_{2}$ mixed gas shielded arc welding. The thickness of the test plate was $12 \mathrm{~mm}$ and welding heat input $(E)$ was $9.2 \sim 26.4 \mathrm{~kJ} / \mathrm{cm}$. The fracture morphology and the fine structures in the HAZ were analysed by means of SEM and TEM. The thin film samples from the HAZ for TEM were obtained using the line cutting method. These samples were ground to thickness $50 \mu \mathrm{m}$ or so, and made into thin film sample that could be penetrated by electron beam. These thin film samples were observed and analysed by using $\mathrm{H}-800$ transmission electron microscope and electron diffraction technique.

\section{Results and analysis}

\subsection{Toughness and fracture morphology in the heat-affected zone}

Effect of the weld heat input $(E)$ on the impact energy in the HAZ of HQ130 super-high strength steel is shown in 
table 2. Impact energy and hardness tend to decrease when the weld heat input $(E)$ changed from $9.2 \mathrm{~kJ}$ to $26.4 \mathrm{~kJ}$. The change of impact energy and hardness had a close relation to microstructure of the HAZ. When $t_{8 / 5}$ ranges from $5 \mathrm{~s}$ to $20 \mathrm{~s}$, microstructure in the HAZ changed from ML to ML + BL.

By using scanning electron microscope (SEM), it was found that when the weld heat input $(E)$ ranges from $9.2 \mathrm{~kJ} / \mathrm{cm}$ to $18.6 \mathrm{~kJ} / \mathrm{cm}$, there were a lot of dimples on the HAZ impact fracture of HQ130 steel and it had an obvious ductile fracture, as shown in figures $1 \mathrm{a}-\mathrm{c}$. But, when $E=26.4 \mathrm{~kJ} / \mathrm{cm}\left(t_{8 / 5}=40 \mathrm{~s}\right)$, the fracture morphology in the HAZ was a quasi-cleavage fracture that had a river pattern feature, and showed an obvious brittleness fracture feature (see figure 1d), corresponding to lower impact energy $\left(A_{\mathrm{KV}}=26 \cdot 5 \mathrm{~J}\right)$.

Under different weld heat inputs, the impact energy of the HAZ has a larger difference, indicating a tendency for a change in the fine structure of the HAZ. The morphology of the lath martensite (ML) has an important effect on the impact toughness in the HAZ of HQ130 steel. The test results indicated that the cooling time $\left(t_{8 / 5}\right)$ should be controlled $\left(t_{8 / 5}=10 \sim 20 \mathrm{~s}\right)$ to improve toughness in the HAZ (corresponding weld heat input is $13.1 \sim 18.6 \mathrm{~kJ} / \mathrm{cm})$. Because, larger the weld heat input, the longer the cooling time $\left(t_{8 / 5}\right)$ and easier for the deterioration of the impact toughness in the HAZ.

\subsection{Fine structure in the HAZ of HQ130 steel}

The SEM test result indicated that microstructure in the HAZ was lath martensite (ML). There was partial BL inside the ML lath, and the laths of BL and ML interacted with each other. ML + BL mixed microstructure in the HAZ has good toughness. Even if there was microcrack inside the $\mathrm{BL}+\mathrm{ML}$ microstructure, these cracks could not propagate easily because of being limited by ML lath boundary. Hence the strength, toughness and ability to resist crack in the HAZ can be assured.

The fine structure of lath martensite in the HAZ of HQ130 steel was analysed using TEM and electron dif-

Table 1. Chemical composition, mechanical properties and phase transformation temperature of HQ130 steel.

\begin{tabular}{|c|c|c|c|c|c|c|c|c|}
\hline \multicolumn{9}{|c|}{ Chemical composition (wt.\%) } \\
\hline $\mathrm{C}$ & $\mathrm{Si}$ & Mn & Mo & $\mathrm{Cr}$ & $\mathrm{Ni}$ & $\mathrm{B}$ & $\mathrm{S}$ & $\mathrm{P}$ \\
\hline $0 \cdot 18$ & $0 \cdot 29$ & $1 \cdot 21$ & $0 \cdot 28$ & $0 \cdot 61$ & 0.03 & $0 \cdot 0012$ & $0 \cdot 006$ & $0 \cdot 025$ \\
\hline \multicolumn{9}{|c|}{ Mechanical properties } \\
\hline$\sigma_{\mathrm{b}}(\mathrm{MPa})$ & & $\sigma_{\mathrm{s}}(\mathrm{MPa})$ & $\delta_{5}(\%)$ & & $\psi(\%)$ & HRC & & $A_{\mathrm{KV}} / \mathrm{J}$ \\
\hline 1370 & & 1313 & 10 & & 43 & $40 \cdot 5$ & & $64(20)$ \\
\hline \multicolumn{9}{|c|}{ Phase transformation temperature $\left({ }^{\circ} \mathrm{C}\right)$} \\
\hline$A c 1$ & & $A c 3$ & $A r 1$ & & Ar3 & $M s$ & & Austenitization \\
\hline 730 & & 850 & 562 & & 754 & 400 & & $920 \pm 10$ \\
\hline
\end{tabular}

Table 2. Effect of the weld heat input on the toughness of HQ130 super-high strength steel.

\begin{tabular}{lccccc}
\hline $\begin{array}{l}\text { Weld heat } \\
\text { input, } E(\mathrm{~kJ})\end{array}$ & $\begin{array}{c}\text { Cooling time, } \\
t_{8 / 5}(\mathrm{~s})\end{array}$ & $\begin{array}{c}\text { Impact energy, } \\
A_{\mathrm{KV}}(\mathrm{J})\end{array}$ & $\begin{array}{c}\text { Microhardness } \\
(\mathrm{HV})\end{array}$ & Microstructure & Fracture morphology \\
\hline 9.2 & 5 & $\begin{array}{c}65 \cdot 7,56 \cdot 1,65 \cdot 4 \\
(62 \cdot 4)\end{array}$ & 372 & ML & Dimple \\
$13 \cdot 1$ & 10 & $\begin{array}{c}55 \cdot 9,51 \cdot 7,53 \cdot 4 \\
(53 \cdot 7)\end{array}$ & 365 & ML & Dimple \\
18.6 & 20 & $\begin{array}{c}60 \cdot 3,55 \cdot 0,46 \cdot 8 \\
(54 \cdot 0)\end{array}$ & 318 & ML + BL & Dimple + Quasi-cleavage \\
26.4 & 40 & $\begin{array}{c}23 \cdot 7,22 \cdot 6,33 \cdot 2 \\
(26 \cdot 5)\end{array}$ & 255 & BL & Quasi-cleavage (QC) \\
\hline
\end{tabular}

Note: Figures in the parentheses were the test average values; ML is lath martensite, BL is lower bainite. 
fraction technique. TEM morphology, electron diffraction pattern and index schematic diagram, taken from [110] direction, are shown in figures $2 \mathrm{a}-\mathrm{c}$. Under TEM, the ML sub-structure is the lath dislocation martensite and the dislocation density is about $(0.3 \sim 0.9) 10^{12} / \mathrm{cm}^{2}$.

Subsequent to tempering, carbide precipitate is distributed inside the martensite lath at the boundary. There is local lattice-deformed zone near the dislocation, where the diffraction strength of electron beam is different than the other parts.

$\gamma \rightarrow \alpha$ (ML) becomes dislocation sub-structure and the crystal direction relation between new and base phases are as follows:

(111) $\gamma / /(001) \alpha$

$$
\text { [101] } \gamma / /[111] \alpha
$$

The parallel twin sub-structure can be occasionally observed except dislocation ML in the HAZ of HQ130 steel under the condition of the low weld heat input $(E=9.2 \mathrm{~kJ} / \mathrm{cm})$. The twin sub-structure and electron diffraction results in the HAZ, as observed by means of TEM and electron diffraction, are shown in figures $3 \mathrm{a}-\mathrm{c}$. But the twin sub-structure inside ML lath is different from the twin in the high carbon steel. The twin substructure in ML appears only in the local zone inside martensite lath and the rest is dislocation line with excellent high density; while the twin structure in high carbon steel is densely arranged and spread all over the martensite base (Yuxu 1985).

Although there is some twin sub-structure in the HAZ of HQ130 steel, the toughness of the basic microstructure is not decreased. The toughness is hardly affected by the little twin sub-structure in a lot of dislocation ML.

When the neighbouring lath crystal is diffracted with selected grating of diameter $20 \mu \mathrm{m}$, the location of diffraction spot in the neighbouring crystal hardly changed but the strength of the diffraction spot changed. This indicated that the difference in direction between ML laths is very small.

The TEM analysis result indicated that the number and morphology of the ML in the HAZ had some differences under different weld heat inputs $(E=9.2 \sim 18.6 \mathrm{~kJ} / \mathrm{cm})$. The carbon gathers near the grain boundary then becomes carbide with Fe, Mn, Mo etc so that the impact toughness decreases. The carbide with strong direction between lath microstructure provides the low energy passage for the impact fracture and increases brittle crack sensitivity. The fine precipitate distributed inside the grain or at the boundary is favourable to improve the toughness. By controlling weld heat input $(E \leq 20 \mathrm{~kJ} / \mathrm{cm})$, the presence of carbide in the HAZ can be removed, and
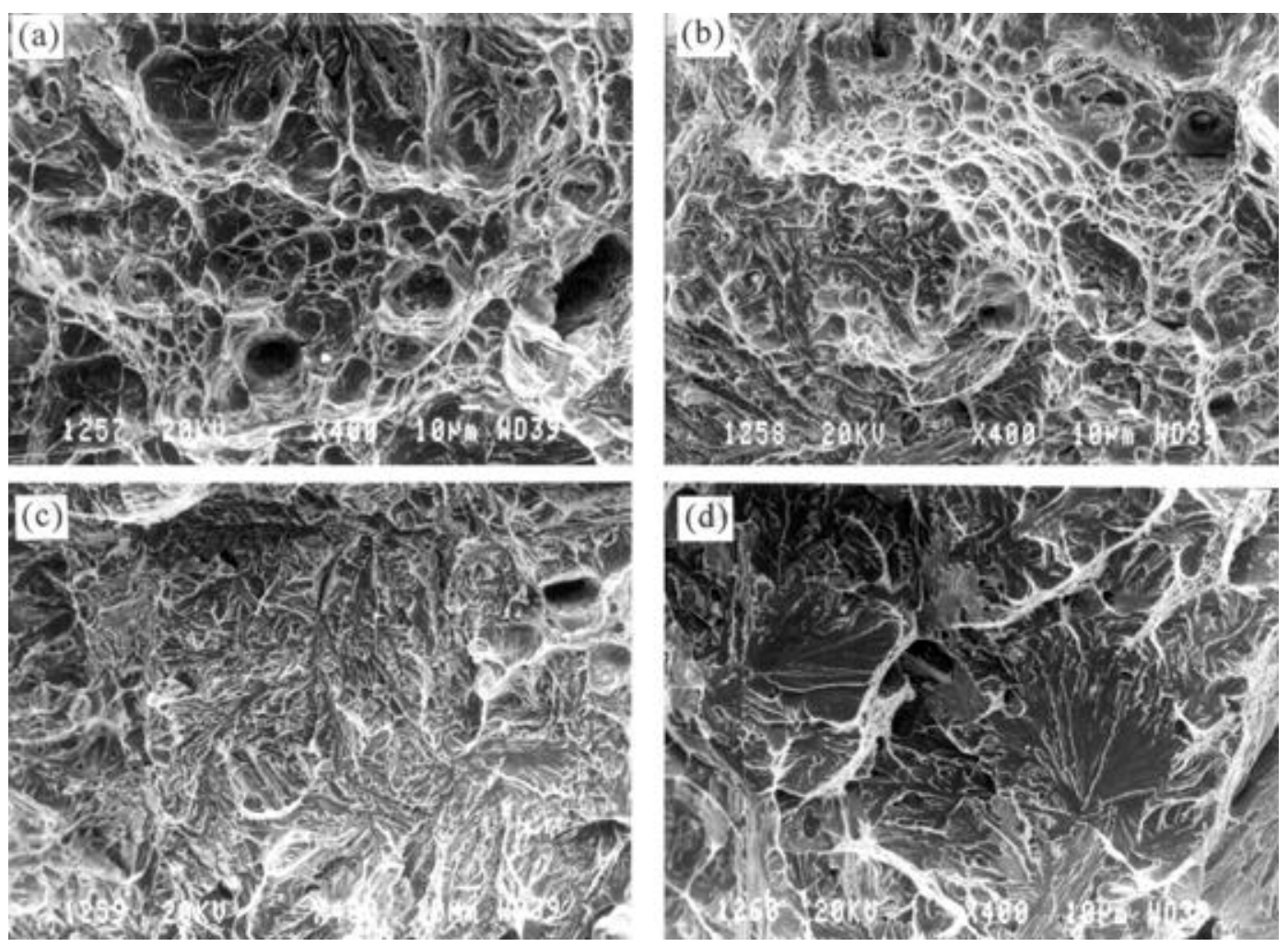

Figure 1. Feature of fracture morphology in the HAZ of HQ130 steel (SEM, 400): (a) $t_{8 / 5}=5 \mathrm{~s}$, (b) $t_{8 / 5}=10 \mathrm{~s}$, (c) $t_{8 / 5}=20 \mathrm{~s}$ and (d) $t_{8 / 5}=40 \mathrm{~s}$. 

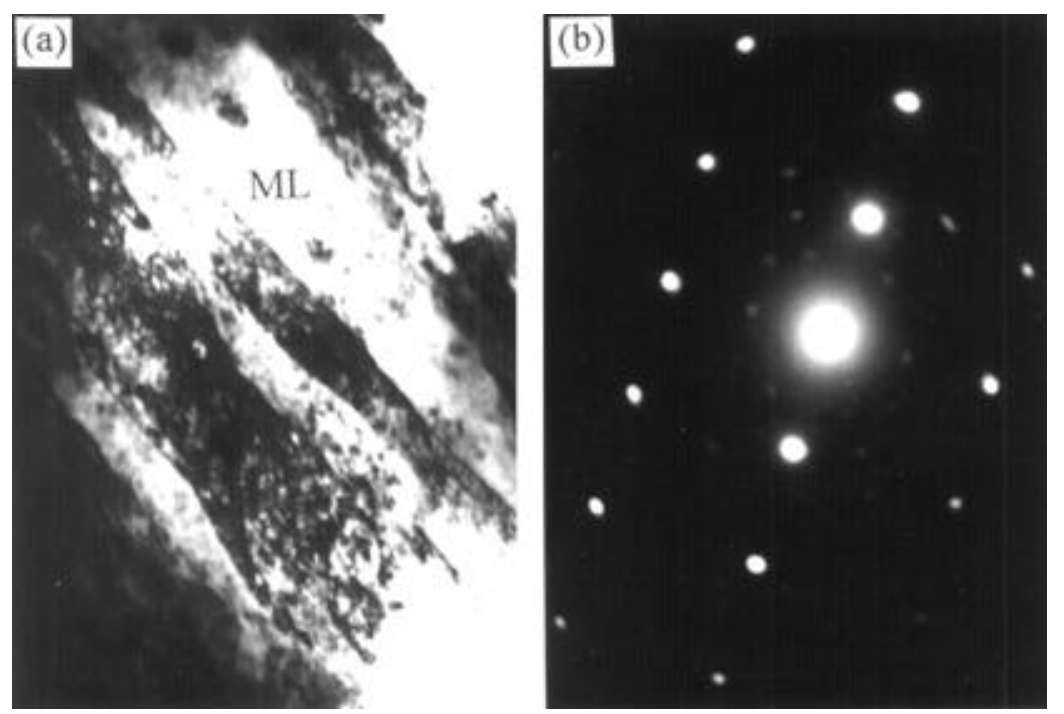

(c)

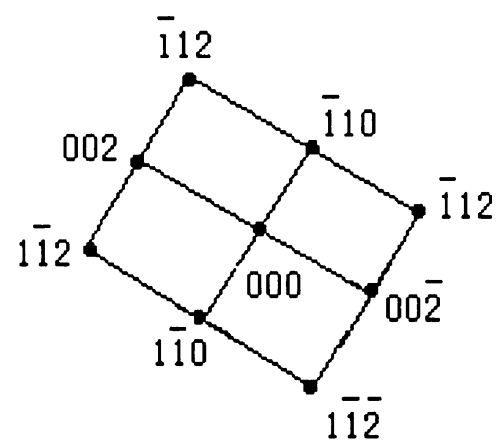

$B=[110]$

Figure 2. Feature of the fine structure in the HAZ of HQ130 steel (TEM): (a) TEM morphology 20,000, (b) electron diffraction pattern and (c) schematic index diagram, $B=[110]$.
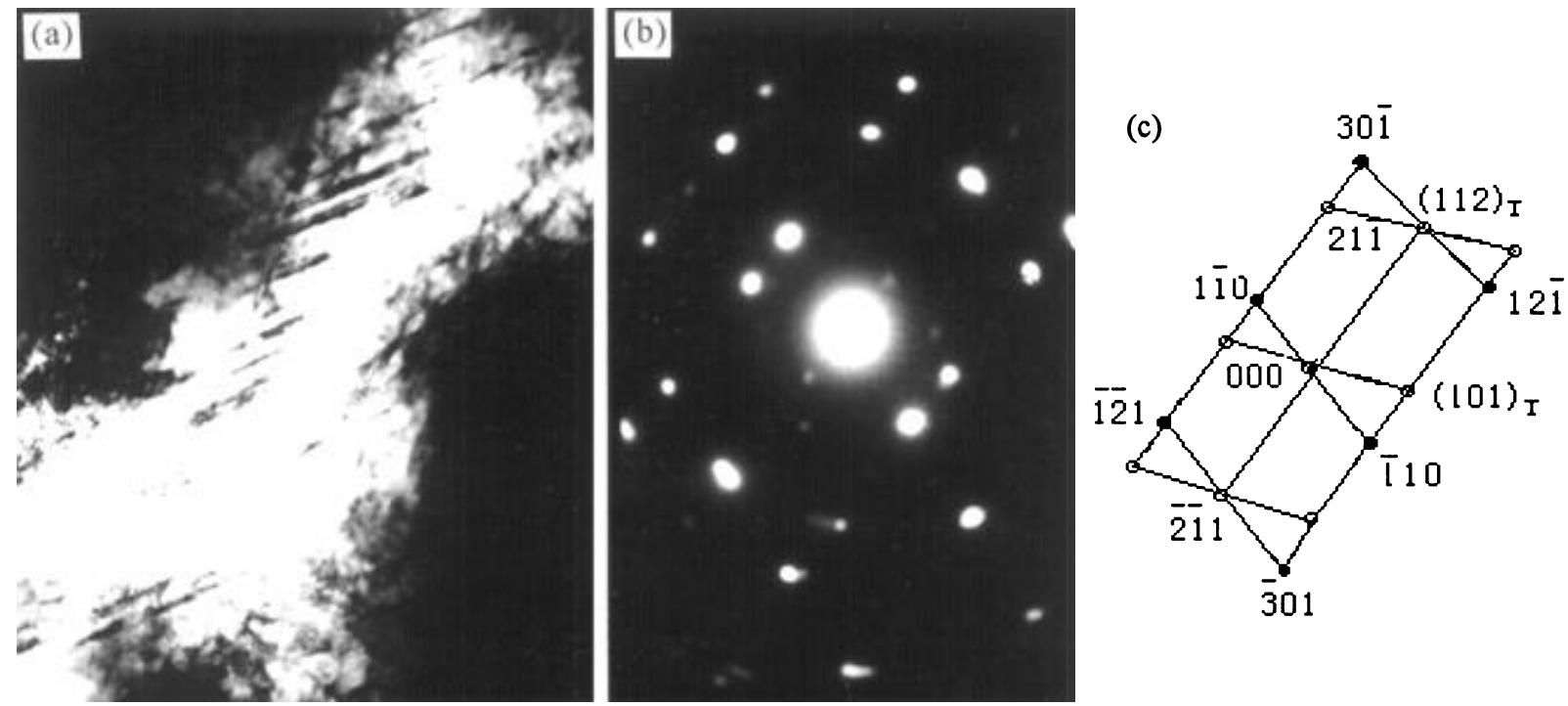

Figure 3. Characteristics of the twin sub-structure in the HAZ of HQ130 steel (TEM): (a) TEM morphology, (b) electron diffraction pattern and (c) schematic index diagram, $B=[113]$.

therefore the impact toughness in this zone can be assured.

\section{Conclusions}

(I) Impact energy in the HAZ of HQ130 steel decreases when the weld heat input $(E)$ changed from $9.2 \mathrm{~kJ} / \mathrm{cm}$ to $26.4 \mathrm{~kJ} / \mathrm{cm}$. In order to ensure toughness, the weld heat input should be strictly limited to $E \leq 20 \mathrm{~kJ} / \mathrm{cm}$.

(II) TEM analysis indicated that the microstructures in the HAZ of HQ130 steel were ML + BL. There exists much dislocation in the sub-structure inside ML lath and the dislocation density is about $(0.3 \sim 0.9) 10^{12} / \mathrm{cm}^{2}$. The twin sub-structure can be occasionally observed in the HAZ but the number is very small. There are no obvious twin sub-structures under the condition of the normal weld heat input $(E=10 \sim 20 \mathrm{~kJ} / \mathrm{cm})$.

(III) By controlling the weld heat input $(E \leq 20 \mathrm{~kJ} / \mathrm{cm})$, the presence of carbide in the HAZ can be removed and the microstructure in this zone can be assured.

\section{Acknowledgement}

This work was supported by the Foundation of National Key Laboratory of Advanced Welding Production Tech- 
nology, Harbin Institute of Technology, People's Republic of China.

\section{References}

Akselen O M et al 1986 Acta Metall. 91807
Guojiu Zhang, Zhaowei Zhou and Hongben Cai 1992 Trans. China Weld. Inst. 113 (in Chinese)

Yajiang Li, Zengda Zou and Zhunian Chen 1997 Trans. China Weld. Inst. 125 (in Chinese)

Yuxu Tan 1985 Acta Metall. 3181

Zengda Zou, Yajiang Li and Shike Yin 1999 J. Mater. Sci. \& Technol. 15555 